\title{
Penjara, Batas, dan Persepsi: Penggabungan Ruang Publik dengan Penjara untuk Mengubah Stigma Negatif Masyarakat
}

\author{
Muhammad Siraj Darami, dan Endy Yudho Prasetyo \\ (ITS) \\ Jl. Arief Rahman Hakim, Surabaya 60111 \\ E-mail: endy_yudho_prasetyo@arch.its.ac.id
}

Jurusan Arsitektur, Fakultas Teknik Sipil dan Perencanaan, Institut Teknologi Sepuluh Nopember

\begin{abstract}
Abstrak- Sebagian besar masyarakat menafsirkan kata penjara sebagai tempat bagi orang-orang yang mutlak berdosa sehingga membentuk pandangan bahwa orang-orang yang keluar dari penjara adalah orang-orang yang harus dihindari dalam pergaulan sehari-hari. Padahal penjara memiliki peran besar terhadap rehabilitasi narapidana demi terciptanya keadilan serta keamanan bagi masyarakat. Demi mengubah persepsi masyarakat serta narapidana terhadap penjara, maka perlu adanya keterlibatan masyarakat terhadap penjara tersebut. Penjara bukan lagi hanya untuk merehabilitasi narapidana dari tindakan kejahatannya, tapi juga mempersiapkan narapidana untuk terjun langsung berkehidupan bermasyarakat pasca menjalani hukuman penjara. maka dari itu area penjara harus dapat dijangkau masyarakat tanpa menghilangkan kaidah keamanan penjara tersebut agar masyarakat dapat merasakan kebermanfaatan penjara dan ikut serta dalam mengembalikan narapidana untuk berkehidupan bermasyarakat. Pada akhirnya hal tersebut akan mengubah persepsi masyarakat terhadap penjara dan narapidana serta persepsi narapidana terhadap penjara itu sendiri.
\end{abstract}

Kata Kunci- batas, masyarakat, narapidana, penjara, persepsi, sosiologi

\section{PENDAHULUAN}

$\mathrm{P}$ idana penjara yang merupakan jenis hukuman pidana dengan merenggut kebebasan dari narapidana untuk menciptakan rasa aman pada masyarakat dan membuat jera pelaku. Perenggutan kebebasan adalah segala bentuk penahanan atau penempatan seseorang pada suatu tempat penahanan, dimana orang tersebut tidak diperkenankan pergi sesukanya, atas perintah suatu pihak kehakiman, administratif, atau pihak umum lainnya

Kata penjara adalah kata yang umum digunakan untuk menggambarkan sebuah tempat hukuman bagi orang yang dikenakan hukuman pidana. Banyak pula yang menafsirkan kata penjara sebagai tempat bagi orang-orang yang mutlak berdosa sehingga membentuk pandangan bahwa orang-orang yang keluar dari penjara adalah orang-orang yang harus dihindari dalam pergaulan sehari-hari. Masyarakat yang memiliki pemikiran tersebut ada karena tidak pernah merasakan secara langsung manfaat dari keberadaan penjara serta berada di dekat objek penjara tentunya akan selalu dihantui paradigma buruk tentang penjara yang sudah banyak menyebar di masyarakat. Pada akhirnya sering timbul banyak penolakan oleh masyarakat terhadap mantan narapidana yang sudak melewati masa tahanan saat kembali untuk berkehidupan bermasyarakat

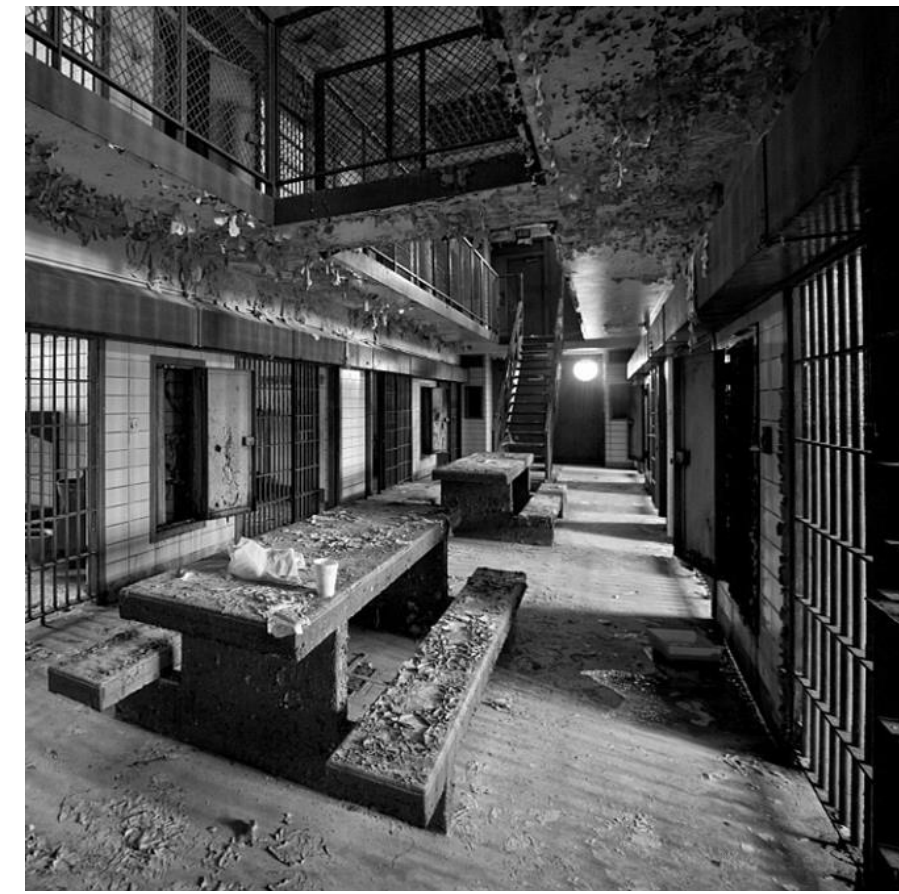

Gambar 1. Ilustrasi Persepsi Masyarakat Terhadap Penjara
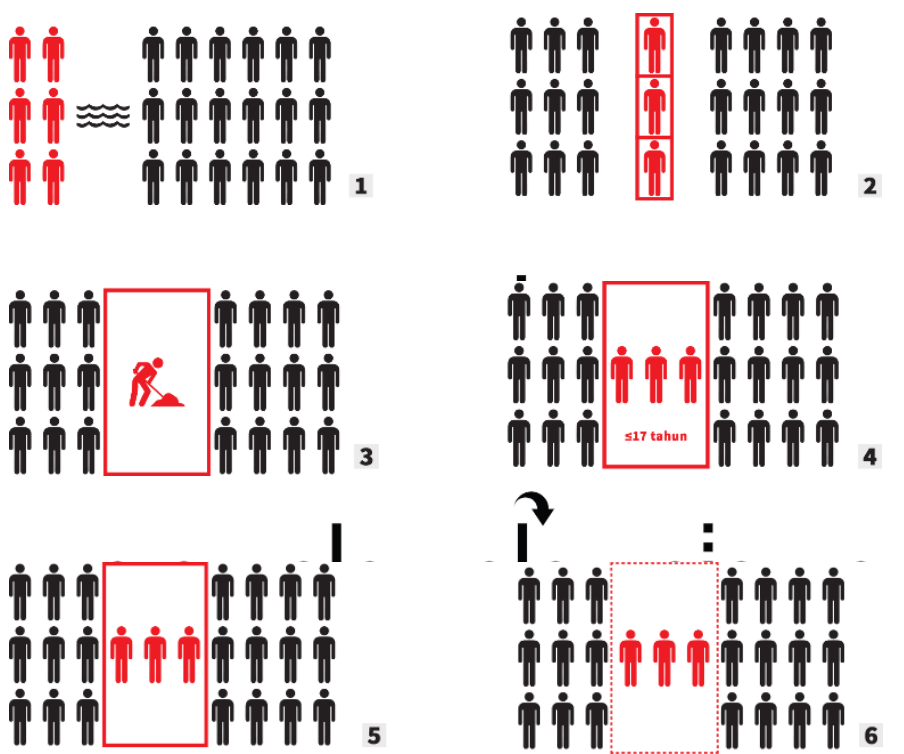

Gambar 2. Diagram Perubahan sistem penjara 
Tentu tidak seharusnya masyarakat menolak kembalinya narapidana ke dalam masyarakat. Hal tersebut juga diperparah dengan kesiapan narapidana dalam berkehidupan di luar penjara. Kesulitan berkomunikasi dengan masyarakat serta terjadinya penolakan terhadap mantan narapidana merupakan masalah yang sering terjadi. Hal tersebut biasanya dikarenakan adanya efek psikologis negatif dari pidana penjara yaitu Loos of personality, security, liberty, personal communication, good and service, heterosexual, prestige, belief, dan creativity. [1]

Sehingga pada akhirnya perlu adanya sistem yang membuat narapidana dan masyarakat dapat membangun hubungan timbal balik baik dari luar dan dari dalam penjara.

Berdasarkan isu yang telah dijelaskan sebelumnya, maka perlu ada perubahan terhadap objek penjara. Tujuan utama dari objek yang akan didesain adalah untuk mengubah persepsi masyarakat mengenai penjara dan narapidana. Persepsi masyarakat yang sangat negatif mengenai penjara serta narapidana membuat ketimpangan sosial antara narapidana dengan masyarakat. Bahkan hal tersebut juga terjadi untuk mantan narapidana. sehingga menimbukan kesulitan bagi narapidana untuk berbaur dengan masyarakat. Perubahan persepsi yang ingin dituju adalah persepsi masyarakat akan menjadi positif terhadap penjara dan narapidana. Persepsi mengenai penjara adalah tempat yang mengerikan serta tempat berkumpulnya orang jahat harus berubah menjadi tempat untuk orang-orang berbenah diri dan menjadi bermanfaat untuk masyarakat. Persepsi mengenai narapidana adalah orang yang mutlak bersalah dan tidak berguna, bahkan disebut sebagai sampah masyarakat juga harus berubah menjadi orang yang dapat berubah serta dapat berkontribusi bagi masyarakat.

Adapun kriteria yang kemudian menjadi acuan desain adalah sebagai berikut:

1. Membangun interaksi antara narapidana dengan masyarakat

2. Membuat fasilitas yang dapat membuat narapidana berkontribusi untuk masyarakat

3. Menghilangkan diskriminasi terhadap narapidana dan mantan narapidana oleh masyarakat

4. Mereduksi batas antara narapidana dengan masyarakat

\section{PENDEKATAN DAN METODE DESAIN}

Pendekatan yang dilakukan dengan pendekatan secara sosiologi. Dalam ilmu sosiologi sendiri banyak menyinggung tentang hubungan antar manusia serta menyinggung kriminalitas. Teori yang digunakan dalam ilmu sosiologi untuk mendesain objek rancangan adalah teori social psychology dan teori social perception. [2]

Untuk menghilangkan dampak buruk yang dihasilkan penjara terhadap narapidana dan masyarakat, maka perlu ada perubahan terhadap penjara itu sendiri. Perubahan dalam penjara tersebut harus dapat mengintergrasikan narapidana dengan masyarakat, menghilangkan stigma buruk dan penolakan dari masyarakat, membuat narapidana berkontribusi terhadap masyarakat, serta merehabilitasi narapidana dengan membatasi narapidana dengan cara yang lebih efektif dan tidak membatasi langsung dengan lingkungan. [3] .
Gambar 3. Diagram Perbandingan Sistem Penjara dengan Sistem Karya Rancangan

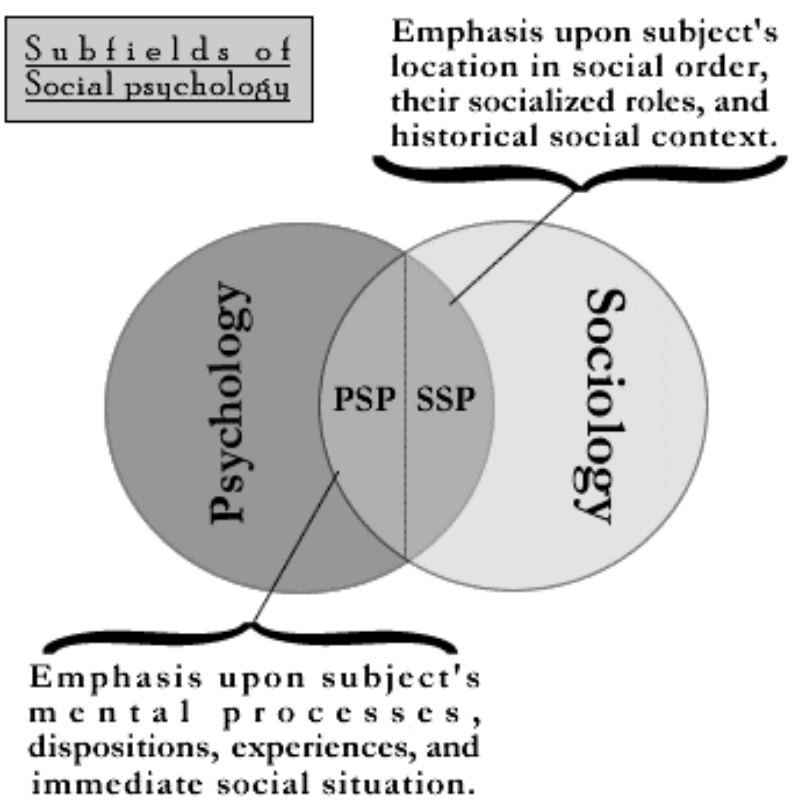

Gambar 4. Diagram psychology-sociology

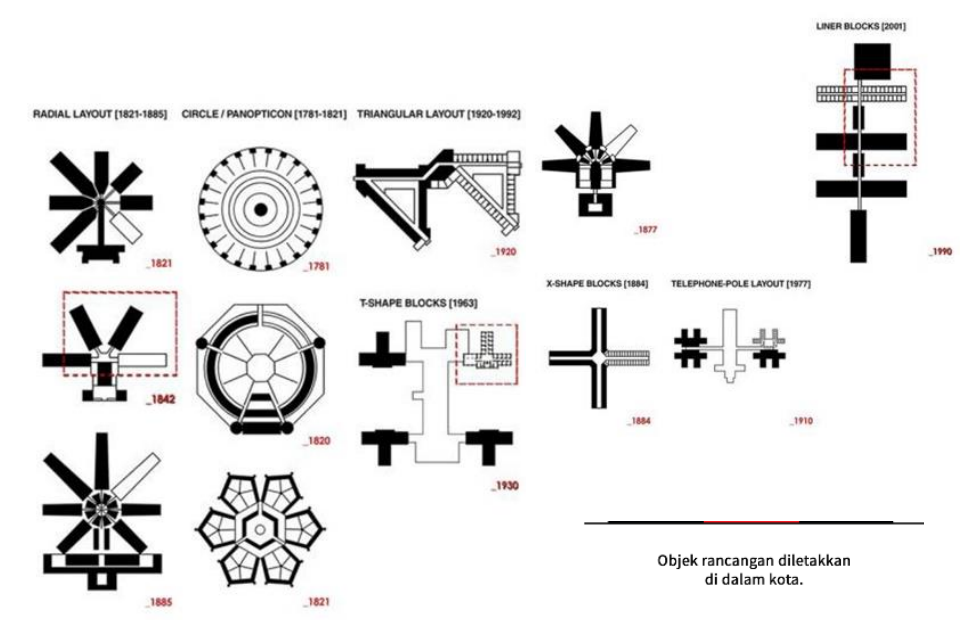

Gambar 5. Jenis Konfigurasi Bangunan Penjara 


\section{PENERAPAN KONSEP}

Dalam konsep pemrograman ruang yang ingin diciptakan pada bangunan ini adalah konsep bahwa penjara tidak hanya untuk menghukum narapidana, melainkan juga untuk merehabilitasi dan membangun interaksi dengan masyarakat dalam menyongsong kehidupan bermasyarakat setelah keluar dari penjara. Maka dilakukan pemrograman pada bgnunan untuk mencapai tujuan tersebut dengan menggabungkan konsep lembaga pemasyarakatan dengan ruang publik dengan tetap memperhatikan kaidah lembaga pemasyarakatan.

Untuk menghilangkan dampak buruk yang dihasilkan penjara terhadap narapidana dan masyarakat, maka perlu ada perubahan terhadap penjara itu sendiri. Perubahan dalam penjara tersebut harus dapat mengintergrasikan narapidana dengan masyarakat, menghilangkan stigma buruk dan penolakan dari masyarakat, membuat narapidana berkontribusi terhadap masyarakat, serta merehabilitasi narapidana dengan membatasi narapidana dengan cara yang lebih efektif dan tidak membatasi langsung dengan lingkungan. Karena dinding sebagai pembatas yang bersifat masiv dan langsung membatasi penjara dengan lingkungan merupakan diskriminasi terbesar pada penjara dan narapidana. [4].

Setelah dilakukan studi tentang batas, akhirnya diketahui bahwaa dalam membatasi ruang gerak manusia dapat menggunakan berbagai macam cara. Sesuai dengan tujuan untuk tidak secara langsung membatasi narapidana dengan dunia luar, maka batas yang digunakan adalah batas dengan elevasi. Dimana bangunan akan dibuat melayang di atas tanah. Dengan demikian maka penggunaan dinding akan dapat direduksi. Penempatan ruang terbuka diletakkan di bagian teratas penjara untuk memberi visual ke area di luar penjara. Demi menciptakan persepsi bahwa narapidana tidak sedang dipisahkan dari masyarakat.

Saat penempatan program utama yaitu bangunan penjara diletakkan melayang dari permukaan tanah, maka tercipta kekosongan pada ruang yang berada di bawahnya yang kemudian digunakan sebagai titik ruang publik yang dapat diakses masyarakat.

Dalam pembentukan bangunan, digunakan grid 2 dimensi yang pemudian dijadikan grid 3 dimensi. Grid tersebut dijadikan acuan dalam pembentukan ruang serta struktur bangunan. Hal tersebut dilakukan untuk mempermudah penggunaan sistem struktur baja yang akan membentuk ruang di dalamnya.

\section{KESIMPULAN}

Penerapan hukuman pidana penjara sendiri sebenarnya dapat diimprovisasi agar berfungsi dengan lebih baik. Salah satu faktor krusial dalam penara, yaitu pembatas, dapat diubah menjadi bentuk yang lain. Penjara yang biasanya menggunakan dinding tinggi sebagai pembatas ternyata bisa digantikan dengan cara menaikkan elevasi dari bangunan. Penggantian pembatas tersebut tetap harus memperhatikan kaidah penjara sendiri. Efek dari penggantian batas tersebut akhirnya dapat mengurangi tingat diskriminasi dari luar penjara serta mengubah persepsi narapidana tentang penjara.

Tidak hanya pengubahan pembatas, tapi juga sebuah

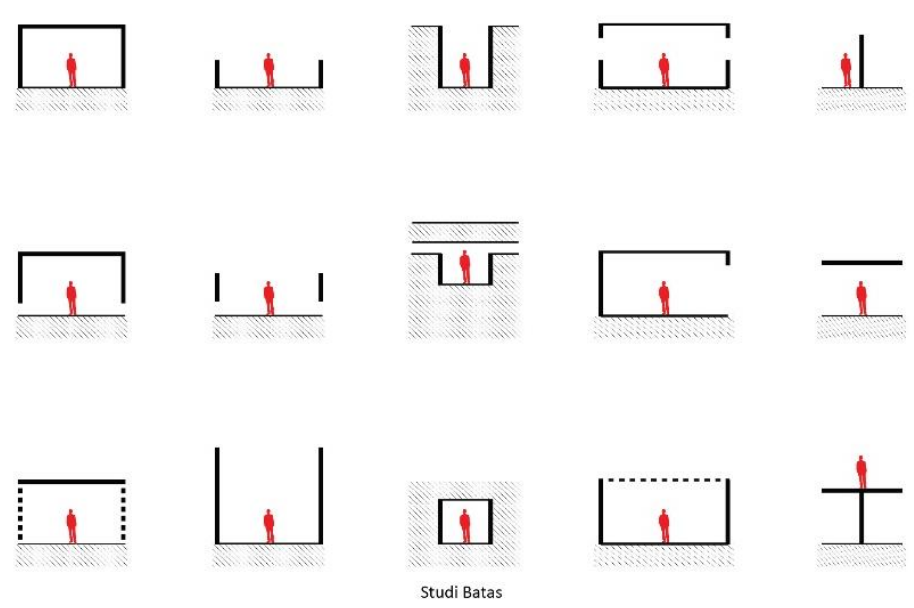

Gambar 6. Studi Batas dan Konsep

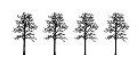
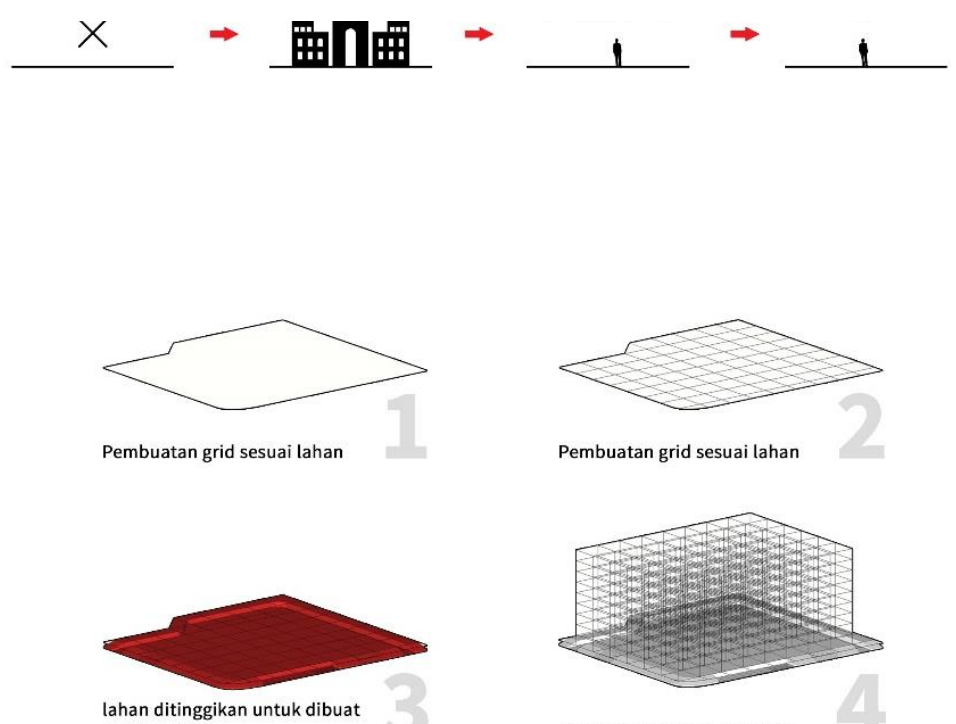

lahan diting

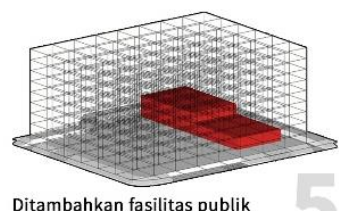

Grid lahan dibuat 3 dimensi sesuai grid

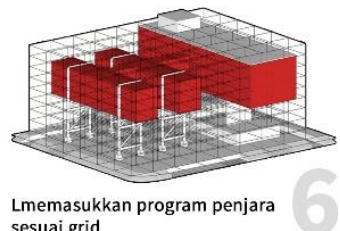
sesuai grid

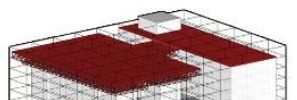

Gambar 7. Implementasi pada Desain

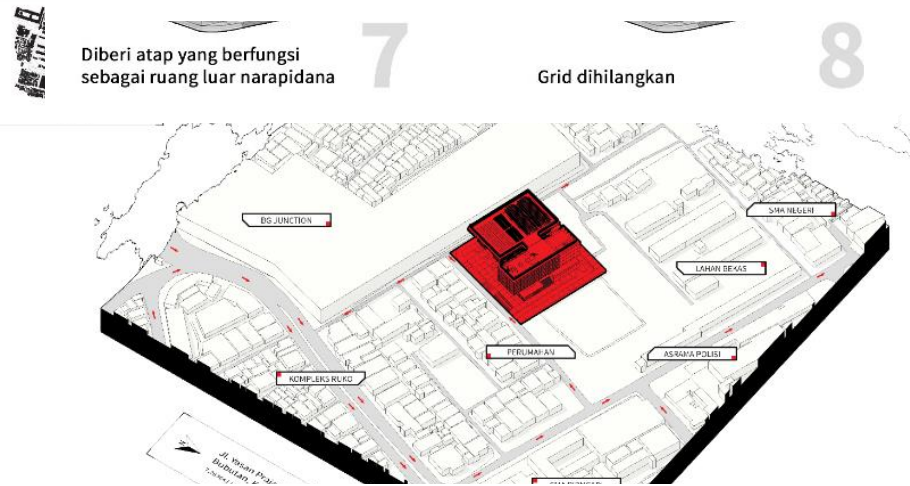

Gambar 8. Karya Rancangan dengan Lingkungan Sekitar 
sistem penjara yang berkelanjutan juga dapat membantu narapidana dalam memulai kembali kehidupan bermasyarakat. Hal tersebut dilakukan dengan menggabungkan antara ruang publik dengan fasilitas penjara. Penggabungan program tersebut bertujuan agar narapidana dapat berkontribusi dan berkomunikasi dengan masyarakat dan masyarakat dapat ikut berkontribusi dalam memasyarakatkan narapidana. Program yang disediakan adalah pasar buah yang buahnya ditanam sendiri oleh narapidana dan dijual narapidana pula. Serta disediakan ruang publik di bagian bawah penjara untuk menarik masyarakat berkunjung ke area penjara.

\section{DAFTAR PUSTAKA}

[1] Haney, Craig. "The Psychological Impact of Incarceration: Implications for Post-Prison Adjustment. U.S. Department of Health and Human Services The Urban Institute. (2001).

[2] Sunarto, Kamanto "Pengantar Sosiologi". Jakarta: Lembaga Penerbitan Fakultas Ekonomi Universitas Indonesia. (2004).

[3] Mauer, Mark. "Thinking About Prison and its Impact in the TwentyFirst Century". Ohio State Journal Of Criminal Law. (2005).

[4] Ellin, Nan “Architecture of Fear". New York: Prineton Architectural Press, Inc. (1997). 